\title{
Visualization of trace-element zoning in fluorapatite using BSE and $C L$ imaging, and EPMA and $\mu$ PIXE/ $\mu$ PIGE mapping
}

\author{
Katarzyna Gros $^{1} \cdot$ Ewa Słaby $^{1}$ - Hans-Jürgen Förster ${ }^{2}$ Przemyslaw P. Michalak ${ }^{3}$. \\ Frans Munnik $^{4}$ • Jens Götze ${ }^{3}$ • Dieter Rhede ${ }^{2}$
}

Received: 16 July 2015 / Accepted: 23 June 2016 / Published online: 5 July 2016

(C) The Author(s) 2016. This article is published with open access at Springerlink.com

\begin{abstract}
In this paper, zonation patterns of trace elements in fluorapatite are discussed that were visualized using four analytical techniques, namely back-scattered electrons (BSE) and cathodoluminescence $(\mathrm{CL})$ imaging, electron probe micro-analysis (EPMA), and micro-proton-induced X-ray/ gamma ray emission ( $\mu$ PIXE/ $\mu$ PIGE) mapping. Each method demonstrates the in-grain compositional variations in a slightly different way. Both BSE and CL provide qualitative data, and the internal textures are displayed in most detail. Additionally, CL points to specific elements enriched in certain growth zones. Qualitative EPMA maps show detailed zonation patterns for specific elements (with high spatial resolution), which are in general correspondence with the patterns observed in BSE and CL images. The $\mu$ PIXE/ $\mu$ PIGE maps are fully quantitative and the detection limits are relatively low compared to EPMA mapping. In present spot measurements $\mu$ PIXE demonstrates lower detection limits than EPMA, however, the latter could be considerably improved by extending the acquisition times. There is no significant overlap of REE (rare earth elements) peaks in the acquired $\mu$ PIXE energy spectra, however, when multiple REEs are
\end{abstract}

Editorial handling: L. Nasdala

Katarzyna Gros

klisowiec@twarda.pan.pl

1 Institute of Geological Sciences, Polish Academy of Sciences, Twarda 51/55, 00-818 Warsaw, Poland

2 Helmholtz-Zentrum Potsdam, Deutsches GeoForschungsZentrum, Telegrafenberg, 14473 Potsdam, Germany

3 Technische Universität Bergakademie Freiberg, 09596 Freiberg, Germany

4 Helmholtz-Zentrum Dresden-Rossendorf, 01314 Dresden, Germany present with sufficiently high concentrations, peak deconvolution may pose some difficulties. Spatial resolution of $\mu$ PIXE/ $\mu$ PIGE images is not sufficiently high to reflect minor textural features, which also result from the greater interaction depth of the proton beam. However, major growth zones are distinguishable. Even though each method has their advantages and limitations, when applied together, they provide an almost complete characterization of compositional variability in trace-element-bearing minerals.

Keywords Trace-element zoning $\cdot$ Fluorapatite $\cdot \mathrm{BSE} \cdot \mathrm{CL}$. EPMA $\cdot \mu$ PIXE $/ \mu$ PIGE

\section{Introduction}

Trace elements, including the rare-earth-elements (REEs), are important petrogenetic indicators and provide useful information about a wide range of processes taking place in magmatic -hydrothermal as well as metamorphic and sedimentary environments. During the last two decades, focus has been placed on their behaviour during magmatic differentiation and postmagmatic fluid-related processes, which can be inferred from whole-rock and mineral chemistry (e.g. Allègre et al. 1977; Sha and Chappell 1999; Belousova et al. 2002; Deering and Bachmann 2010). Detailed investigation of trace-element contents in minerals and their spatial variations within single grains provide insight into the dynamics of magmatic differentiation and chemical heterogeneities within the melt from which these minerals crystallized (e.g. Dempster et al. 2003; Słaby et al. 2007a, b; Streck 2008; McLeod et al. 2011; Churikova et al. 2013). Therefore, a high-resolution visualization of compositional zoning in accessory minerals, the major carriers of the REEs, is necessary for fully revealing their growth history. 
Several analytical methods for textural and compositional imaging, such as backscattered electrons (BSE) and cathodoluminescence (CL) imaging and electron probe micro-analysis (EPMA) are routinely applied in petrogenetical and geochemical studies (e.g. Ginibre et al. 2002; Reed 2005; Götze et al. 2013 and references therein; North-Valencia et al. 2014; Wiedenbeck et al. 2014). Although all of those permit visualizing of growth textures in minerals, the information given by each of them is unique due to different physical principles each method is based on. Back-scattered electrons images primarily demonstrate variations in the relative electron density ( $\bar{Z}$ contrast). The contrast is displayed using a grey-scale, where brighter tones indicate a higher mean atomic number, for instance corresponding to relative enrichment of fluorapatite in heavy elements, such as REEs (e.g. Lloyd 1987). However, the intensity of the BSE signal may also depend on crystal orientation if differently oriented crystals of one mineral species are considered (crystal orientation contrast; e.g. Lloyd 1987; Prior et al. 1999), structural variations, for instance among polymorphs of the same chemical compound (phase contrast; e.g. Mosenfelder 2000; Nasdala et al. 2007) and structural defects such as dislocations or micro-porosity (electron channelling contrast; e.g. Kaneko et al. 2005; Nasdala et al. 2007, 2009). Cathodoluminescence imaging reveals the presence of specific structural defects, e.g. vacancies or impurities in the form of trace elements. These cause electron excitation during interaction with an electron beam and induce luminescence of varying energy (Götze et al. 2013). Therefore, the growth zoning revealed by CL usually enables one to distinguish among domains of different origin. However, elevated contents of some ions (e.g. $\mathrm{Fe}^{2+}$ or $\mathrm{As}^{5+}$ ) in the mineral structure can result in significant quenching of the luminescence intensity, which may limit the amount of information provided by CL (e.g. Filippelli and Delaney 1993; Perseil et al. 2000; Kempe and Götze 2002). The compositional zoning can be further demonstrated by elemental-distribution maps, e.g. obtained by EPMA. These maps can be produced for each element present above its detection limit and with a lateral resolution comparable to those of BSE and CL images (e.g. NorthValencia et al. 2014). However, longer acquisition times and, hence, longer sample exposure to the electron beam may inhibit mapping of certain elements, e.g. Na or F. Measurement of $\mathrm{F}$ in some minerals, for instance fluorapatite, is problematic owing to diffusion of $\mathrm{F}$ under the electron-beam irradiation promoted by specific crystallographic orientations (e.g. Stormer et al. 1993; Stock et al. 2015). Mobility of Na during EPMA measurement has been documented in glasses and some minerals (e.g. Nielsen and Sigurdsson 1981; Spray and Rae 1995; Morgan and London 1996). However, applying shorter acquisition times and lower accelerating voltage (12$15 \mathrm{kV}$ ) can: 1) significantly minimize the diffusion and mobility and 2) improve the sensitivity of both $\mathrm{F}$ and $\mathrm{Na}$. For trace elements, e.g. REEs, significantly longer acquisition times are required.

Less conventional X-ray based methods that are being applied for imaging zonation patterns are micro-particle-induced $\mathrm{X}$-ray emission ( $\mu \mathrm{PIXE})$ and micro-particle-induced gamma ray emission ( $\mu$ PIGE) (Reimold et al. 1999; Habermann et al. 2000; Ryan 2000, 2011; Vagelli et al. 2003; Dekov et al. 2013; Li et al. 2013; Fuchs et al. 2014). In these techniques, an ion beam (usually protons) is used to induce characteristic X-rays (for elements with $Z>11$ ) or gamma rays (for light elements with $Z<16$ ). Advantages of these methods over the more conventional X-ray-based methods include generally lower detection limits in mapping, an improved ability to measure light elements (e.g. Na and F), and no need for calibration standards for concentration calculations.

The present study aims at comparing the usability of the aforementioned methods in visualization of compositional zoning in small minerals and evaluating the differences in quality of the obtained results, generally applying standard "routine" measuring conditions. The criteria that we discuss include spatial resolution of the obtained images, detection limits, interaction volume, separation of the relevant element peaks and overall data-acquisition time. As an example we use REE-bearing fluorapatite $\left(\mathrm{Ca}_{5}\left(\mathrm{PO}_{4}\right)_{3}[\mathrm{~F}, \mathrm{Cl}, \mathrm{OH}]\right)$, which is often zoned and contains variable amounts of REEs. Fluorapatite is a challenging mineral in terms of chemical analysis because it commonly contains elements of widely differing atomic number. Analytical problems are due to 1) the coexistence of light and heavy elements which usually require different measurement conditions, and 2) energy lines which may overlap with each other, e.g. K-lines of light elements are located in the same energy range as L- and M-lines of heavy elements. The advantages and limitations of each technique are discussed based on the differences in information obtained by each analytical method.

\section{Samples and analytical methods}

Investigated fluorapatite grains come from the Karkonosze granitoid batholith forming the central part of the Karkonosze - Izera Massif (Western Sudetes, SE Poland, NE Czech Republic). The pluton is composed of many different types of rocks covering a wide range of silica content (49$78 \mathrm{wt} \%$ ) and is formed mostly by mixing of mantle-derived lamprophyric and crust-derived granitic magmas (e.g. Słaby et al. 2007a, b; Słaby and Martin 2005, 2008). Rock samples used in the present study include three granodiorites - RUD1, RUD2, FOJ, one porphyritic granite - MIL, and equigranular granite - EQU. Fluorapatite crystals are usually $20-200 \mu \mathrm{m}$ in size and demonstrate complex zonation patterns, indicating significant trace-element variations during crystal growth (Przywóski 2006; Słaby 2006; Lisowiec et al. 2015). Grains 
were separated from the crushed and sieved rock by a combination of magnetic and heavy liquid (LST Fastfloat, Polytungstates Europe, Chippenham, UK) separation methods and subsequently prepared as polished grain mounts embedded in epoxy.

Back-scattered electrons and CL images as well as EPMA and $\mu \mathrm{PIXE} / \mu \mathrm{PIGE}$ elemental distribution maps were collected for five fluorapatite grains - EQU-1ap, RUD1-5ap, RUD14ap, MIL-4ap, RUD2-12ap. Spot measurements were performed for an additional fluorapatite grain separate (FOJ5ap) by EPMA and $\mu$ PIXE. BSE images were acquired using a FEI Quanta 650 MLA-FEG scanning electron microscope operating at $25 \mathrm{kV}$ accelerating voltage and $1 \mathrm{nA}$ electron beam current (Table 1 ).

Cathodoluminescence direct images were obtained using a "hot cathode" CL microscope HC1-LM (cf. Neuser et al. 1995). Such a system is characterized by a defocused electron beam, therefore the luminescence image is obtained from the entire irradiated area. The system operated at $14 \mathrm{kV}$ accelerating voltage and a beam current of $0.2 \mathrm{~mA}$ (current density of about $10 \mu \mathrm{A} / \mathrm{mm}^{2}$ ) (Table 1). Thin-sections were placed upside-down and irradiated from below (the emitted luminescence is observed through the entire thin-section ). Luminescence images were captured "on-line" during CL operations using a Peltier cooled digital video-camera (OLYMPUS DP72). Cathodoluminescence spectra in the wavelength range 390 to $1000 \mathrm{~nm}$ were recorded with an Acton Research SP-2356 digital triple-grating spectrograph with a Princeton Spec-10 CCD detector that was attached to the CL microscope by a silica-glass fiber guide. Spectra were measured under uniform conditions (wavelength calibration by a Hg-halogen lamp, spot width $30 \mu \mathrm{m}$, measuring time $1 \mathrm{~s}$ ).

Qualitative elemental distribution maps were collected using a field-emission electron probe micro-analyzer (JEOL JXA-8500 F). The analytical conditions for elemental mapping included an acceleration voltage of $20 \mathrm{kV}$, a beam current of $20 \mathrm{nA}$, and a beam size of $1 \mu \mathrm{m}$ (see Table 1). Depending on the size of the respective fluorapatite grain and actual chemical composition, dwell times per pixel were set to 400-2000 ms. Both maps and single-spot analyses were performed in the WDS (wavelength-dispersive spectrometry) mode (using five spectrometers, containing LDE1, TAP, LIF, PET and PETH crystals). This was done because the main focus of the present study are minor and trace elements. The analytical conditions for quantitative spot analysis included an acceleration voltage of $20 \mathrm{kV}$, a beam current of $10 \mathrm{nA}$, and a beam diameter of $10 \mu \mathrm{m}$ (to minimize diffusion of $\mathrm{Na}$ and $\mathrm{F}$ ) (Table 1). Reference materials, X-ray lines, WDS crystals, counting times, and detection limits for all elements are quoted in Table 2. The background counting times were always set to one half of the respective peak counting time. The CITZAF routine in the JEOL software, which is based on the $\Phi(\rho Z)$ method (Armstrong 1995), was used for data processing.

The principles of $\mu$ PIXE are given in Johansson et al. (1995) and Wang and Nastasi (2010) and are briefly reviewed here. It is a relatively non-destructive, standard-free method based on the interaction between an accelerated high-energy $(\mathrm{MeV})$ ion beam (usually protons) and sample atoms, resulting in their ionization and emission of characteristic $\mathrm{X}$ rays. The high mass of ions, even protons, compared to electrons reduces the primary bremsstrahlung and thus increases the sensitivity compared to a method based on X-ray emission, such as EPMA. The $\mathrm{X}$-ray radiation is usually collected by an energy-dispersive detector. Depending on the type of studied material and measurement conditions, the method is capable of routine quantitative analysis of elements from $\mathrm{Na}$ to $\mathrm{U}$, with limits of detection in the range of 10 to $100 \mathrm{ppm}$. Simultaneously to $\mu$ PIXE, $\mu$ PIGE can be applied to detect gamma rays produced by nuclear reactions between the ions (mostly protons or deuterium) and sample atoms, by connecting an additional detector to the experimental chamber. Because the protons have to overcome the Coulomb barrier of the sample atoms' nuclei, mainly light elements $(\mathrm{Z}<$ 16), such as $\mathrm{Li}, \mathrm{Be}, \mathrm{B}, \mathrm{F}, \mathrm{Na}$, and $\mathrm{Al}$, are detectable by this method, which therefore is complementary to $\mu$ PIXE.

The $\mu \mathrm{PIXE} / \mu \mathrm{PIGE}$ measurements were performed at a microbeamline set-up connected to a HVEE $3 \mathrm{MV}$ Tandetron Accelerator. The beamline is kept under high vacuum and is several meters long, along which the beam is guided and focused on the sample holder in the sample chamber. Operating conditions were: proton beam, $3.5 \mathrm{MeV}$ beam energy, $1 \mathrm{nA}$ beam current and $5 \times 5 \mu \mathrm{m}^{2}$ beam size (Table 1 ). A Silicon Drift Detector (SDD) collimated to $80 \mathrm{~mm}^{2}$ area was used for $\mu$ PIXE with an energy resolution of $145 \mathrm{eV}$ (for $\mathrm{Mn}-\mathrm{K} \alpha$ ) and an HPGe detector with a relative efficiency of $76 \%$ and an energy resolution of $2 \mathrm{keV}$ for $1332 \mathrm{keV}$ gamma rays was applied for $\mu$ PIGE. Mylar absorbers of varying thickness $(50,130,230 \mu \mathrm{m})$ were used in front of the $\mu$ PIXE detector in order to attenuate the $\mathrm{Ca}$ and $\mathrm{P} \mathrm{K}$-lines intensities, which are major elements of fluorapatite. These
Table 1 Compilation of analytical parameters of the four techniques

\begin{tabular}{llll}
\hline Method & Accelerating voltage & Beam current & Beam diameter/ spot width \\
\hline BSE & $25 \mathrm{kV}$ & $1 \mathrm{nA}$ & - \\
CL & $14 \mathrm{kV}$ & $0.2 \mathrm{~mA}$ & $30 \mu \mathrm{m}$ \\
EPMA & $20 \mathrm{kV}$ & $20 \mathrm{nA}$ & $1 \mu \mathrm{m}$ (mapping) $10 \mu \mathrm{m}$ (spot analysis) \\
$\mu$ PIXE/ $\mu$ PIGE & $3.5 \mathrm{MeV}$ & $1 \mathrm{nA}$ & $8 \times 5 \mathrm{~m}^{2}$ \\
\hline
\end{tabular}


extra layers reduce the transmission for low energy X-rays and, therefore, decrease the detection efficiency for low $\mathrm{Z}$ elements. The HPGe detector is also mounted outside the sample chamber, separated with a $1-\mathrm{cm}$ glass window and approximately $1 \mathrm{~cm}$ of air from the sample. This only reduces the transmission for the lowest energy gamma rays (between 100 and $200 \mathrm{keV}$ ). X-ray lines and detection limits for all elements are given in Table 2. Total acquisition time for one elemental-distribution map was 3-4 h. Spot measurements were performed similar to the mapping, but a smaller area (ca. $3 \times 3$ pixels) was selected for spectrum acquisition. The Gupix software (Campbell et al. 2000) was used to reduce the analytical data.

\section{Results}

\section{BSE and CL imaging}

The BSE and CL images (see top rows in Figs. 1, 2, and 3) display in detail the zonation patterns within fluorapatite crystals. Differences in BSE intensity allow us to distinguish among growth stages within the grains and their specific characteristics. Large contrasts imply major compositional variations between adjacent zones (e.g. top rows in Figs. 1a-b, 2b). Automatic adjustment of the BSE contrast does not allow the distinction of thin zones several micrometers in size if the compositional contrast is too small. In this situation, CL is the superior technique as it is usually more sensitive to growth zones in fluorapatite (e.g. MacRae et al. 2012). Here, zones as narrow as $1-2 \mu \mathrm{m}$ are distinguishable. However, by using manually enhanced contrast settings, the level of details in BSE images can match the quality shown by CL images. Apart from irregular or primary growth zoning, additional features visible on BSE and CL images include microinclusions of other minerals (e.g. top rows in Figs. 1b, 2b), cracks (seen slightly better on BSE images, e.g. top rows in Figs. 1a, 2b) and dissolution boundaries (recognizable in both types of images, e.g. top rows in Figs. 2a, 3). Cathodoluminescence of fluorapatite is basically activated by two ions or groups of ions: $\mathrm{Mn}^{2+}$-yellow luminescence and $\mathrm{REE}^{3+}$ - violet/blue luminescence (Götze et al. 2001; Kempe and Götze 2002; Götze 2012). Even slight variations in concentration of these elements at the ppm level cause a variation in the peak intensity, producing a change in the overall luminescence and, therefore, makes it possible to distinguish growth domains. Such zones may be indiscernible in BSE images (e.g. the two innermost zones in grain RUD14ap, top-left image in Fig. 2a), but visible using CL because of different amounts of REE and/or Mn in the fluorapatite structure. (top-right image in Fig. 2a).

In addition, $\mathrm{CL}$ wavelength spectra were collected from both zones (yellow and violet) of the grain RUD1-5ap (Fig. 4). The $\mathrm{Mn}^{2+}$-activated band is present only in the yellow-zone located at around $580 \mathrm{~nm}$ (dashed line in Fig. 4). It has one of the highest intensities (next to $D y^{3+}$ ), which is expressed by this dominating yellow luminescence. Bands activated by $\mathrm{REE}^{3+}$ are also present, they are however

Table 2 Analytical parameters of spot measurements performed by EPMA and $\mu$ PIXE

\begin{tabular}{|c|c|c|c|c|c|c|c|}
\hline Element & $\mathrm{X}$-ray line EPMA & WDS crystal & Counting time $[\mathrm{s}]$ & Calibrant & $\begin{array}{l}\text { Detection limit } \\
\text { EPMA [ppm] }\end{array}$ & X-ray line $\mu$ PIXE & $\begin{array}{l}\text { Detection limit } \\
\mu \text { PIXE [ppm] }\end{array}$ \\
\hline $\mathrm{F}$ & $\mathrm{K} \alpha$ & LDE1 & 20 & $\mathrm{CaF}_{2}$ & 470 & - & - \\
\hline $\mathrm{Na}$ & $\mathrm{K} \alpha$ & TAP & 10 & Albite & 270 & - & - \\
\hline $\mathrm{Ca}$ & $\mathrm{K} \alpha$ & PETH & 10 & Apatite & 90 & $\mathrm{~K} \alpha$ & 66 \\
\hline $\mathrm{Mn}$ & $\mathrm{K} \alpha$ & $\mathrm{LiF}$ & 20 & Rhodonite & 200 & $\mathrm{~K} \alpha$ & 17 \\
\hline $\mathrm{Fe}$ & $\mathrm{K} \alpha$ & $\mathrm{LiF}$ & 20 & Hematite & 190 & $\mathrm{~K} \alpha$ & 16 \\
\hline As & - & - & - & - & - & $\mathrm{K} \alpha$ & 4 \\
\hline $\mathrm{Sr}$ & $\mathrm{L} \alpha$ & TAP & 20 & Celestite & 320 & $\mathrm{~K} \alpha$ & 4 \\
\hline $\mathrm{Y}$ & $\mathrm{L} \alpha$ & TAP & 50 & $\mathrm{YPO}_{4}$ & 180 & $\mathrm{~K} \alpha$ & 10 \\
\hline $\mathrm{Zr}$ & - & - & - & - & - & $\mathrm{K} \alpha$ & 14 \\
\hline $\mathrm{La}$ & $\mathrm{L} \alpha$ & $\mathrm{LiF}$ & 50 & $\mathrm{LaPO}_{4}$ & 470 & $\mathrm{~L} \alpha$ & 86 \\
\hline $\mathrm{Ce}$ & $\mathrm{L} \alpha$ & $\mathrm{LiF}$ & 50 & $\mathrm{CePO}_{4}$ & 410 & $\mathrm{~L} \alpha$ & 67 \\
\hline $\mathrm{Nd}$ & $\mathrm{L} \beta$ & $\mathrm{LiF}$ & 50 & $\mathrm{NdPO}_{4}$ & 480 & $\mathrm{~L} \alpha$ & 121 \\
\hline $\mathrm{Tm}$ & $\mathrm{L} \beta$ & $\mathrm{LiF}$ & 50 & $\mathrm{TmPO}_{4}$ & - & $\mathrm{L} \alpha$ & 34 \\
\hline $\mathrm{Yb}$ & $\mathrm{L} \alpha$ & $\mathrm{LiF}$ & 50 & $\mathrm{YbPO}_{4}$ & 260 & $\mathrm{~L} \alpha$ & 44 \\
\hline $\mathrm{Hf}$ & - & - & - & - & - & $\mathrm{L} \alpha$ & 22 \\
\hline Th & $\mathrm{M} \alpha$ & PETH & 50 & Th-metal & 110 & $\mathrm{~L} \alpha$ & 12 \\
\hline $\mathrm{U}$ & $\mathrm{M} \beta$ & PETH & 50 & U-metal & 160 & $\mathrm{~L} \alpha$ & 14 \\
\hline
\end{tabular}




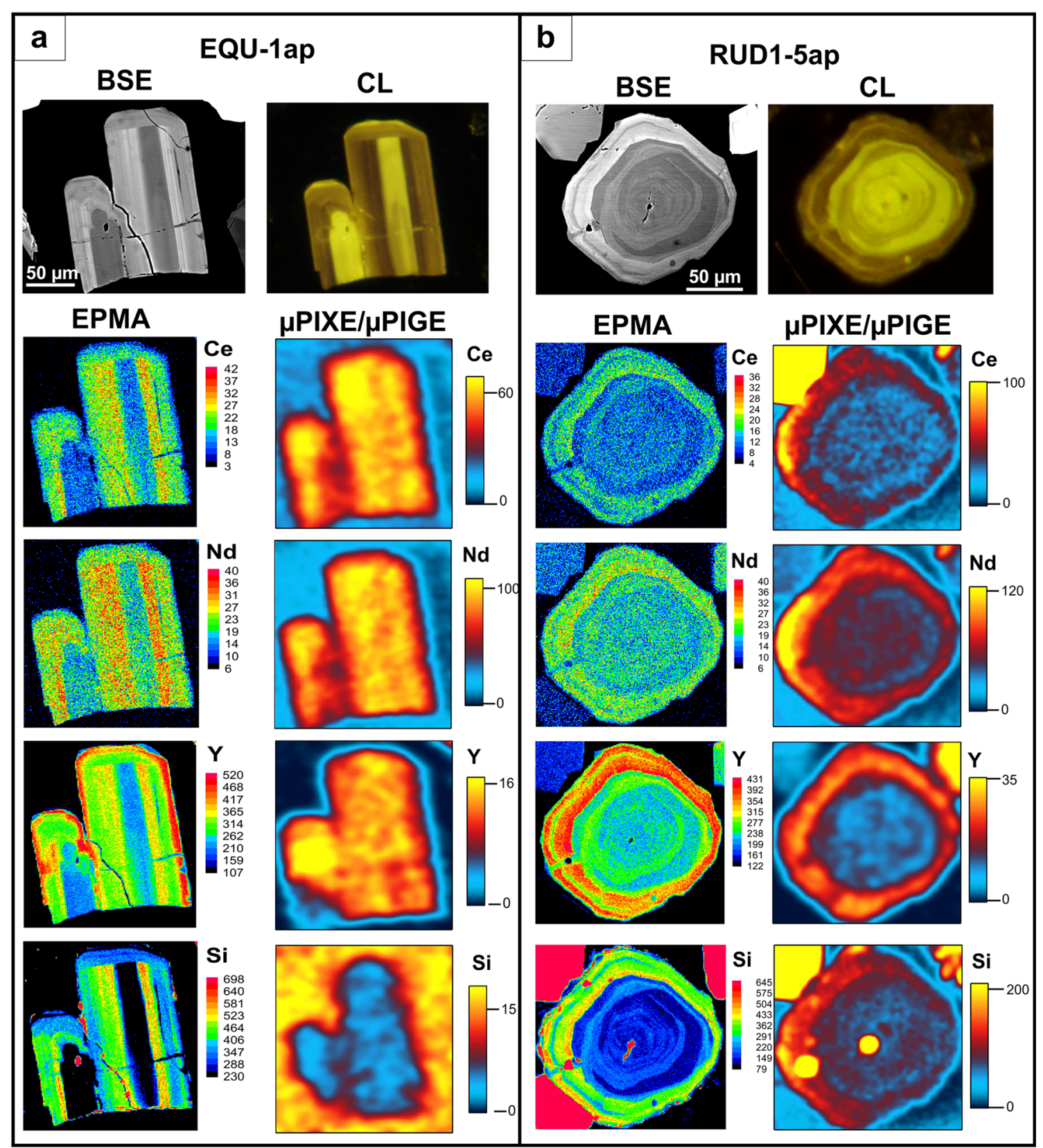

Fig. 1 Backscattered electrons (BSE; top-left), cathodoluminescence (CL; top-right) images, EPMA (bottom-left column) and $\mu$ PIXE/ $\mu$ PIGE (bottom-right column) elemental distribution maps of two fluorapatite

grains: a - EQU-1ap, b - RUD1-5ap. Ce, Nd and Y were measured by $\mu$ PIXE, Si by $\mu$ PIGE. Color scale in EPMA and $\mu$ PIXE/ $\mu$ PIGE maps represents the intensity of collected X-rays [counts]

more pronounced in the violet-zone spectrum (full line in Fig. 4). These include $\mathrm{Dy}^{3+}$ bands at around 480 and $580 \mathrm{~nm}, \mathrm{Sm}^{3+}$ bands at around 600,640, 700 and $800 \mathrm{~nm}$, and $\mathrm{Nd}^{3+}$ bands at around $870-900 \mathrm{~nm}$ Additionally, a very faint $\mathrm{Tb}^{3+}$ peak can be recognized at $550 \mathrm{~nm}$. A wide band near $\sim 400 \mathrm{~nm}$ probably represents "intrinsic" electron defects related to oxygen in the $\mathrm{PO}_{4}$ groups (Götze 2012). Violet-blue luminescence demonstrated by this particular zone is probably a result of a combination of all present $\mathrm{REE}^{3+}$, intrinsic electron defects and the absence of the $\mathrm{Mn}^{2+}$-activated band.

\section{EPMA imaging}

The EPMA elemental distribution maps of fluorapatite accurately reflect the compositional variations in single grains and reproduce the zonation patterns seen in the BSE and CL images (bottom-left column in Figs. 1, 2, and 3). The pixel size of $1 \times 1 \mu^{2}$ was sufficiently small to document even the thinnest growth zones (e.g. bottom-left column in Figs. 1b, 2a). All mapped elements are usually positively correlated. Zones enriched in all of them are also those which display violet luminescence $(\mathrm{Nd}$ is one of the $\mathrm{CL}$ activators, however, 


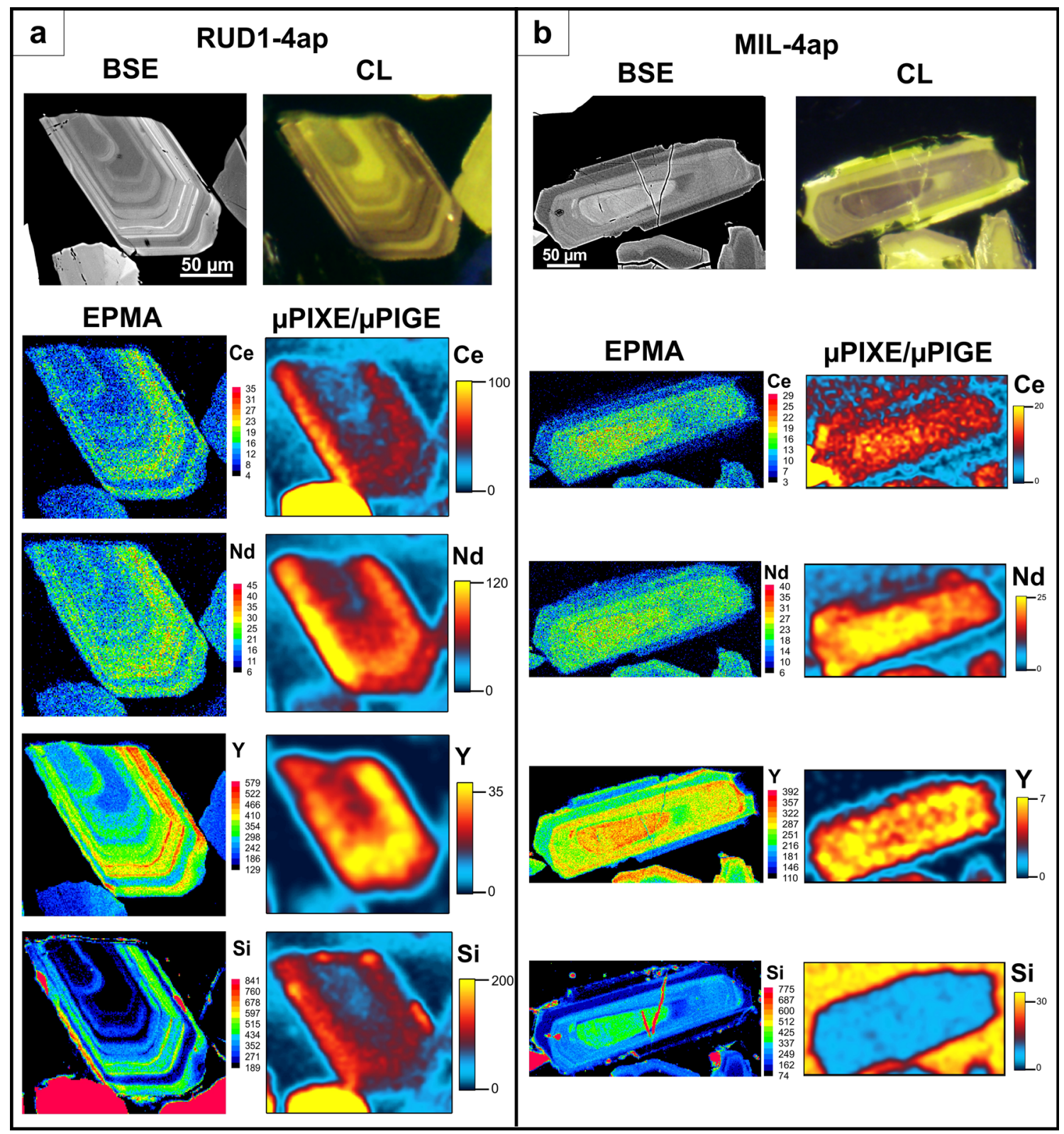

Fig. 2 Backscattered electrons (BSE; top-left), cathodoluminescence (CL; top-right) images, EPMA (bottom-left column) and $\mu$ PIXE/ $\mu$ PIGE (bottom-right column) elemental distribution maps of two fluorapatite

grains: a - RUD1-4ap, b - MIL-4ap. Ce, Nd and Y were measured by $\mu$ PIXE , Si by $\mu$ PIGE. Color scale in EPMA and $\mu$ PIXE/ $\mu$ PIGE maps represents the intensity of collected X-rays [counts]

the luminescence is the combined result of a greater spectrum of REEs). Differences in the spatial resolution of the EPMA maps can be observed between: 1) individual elements - Ce and Nd exhibit lower level of details compared to Si and Y due to lower concentrations and, thus, the intensity of the X-ray signal; and 2) individual fluorapatite grains, mostly due to different acquisition times (for grain RUD2-12ap, Fig. 3 - 6$7 \mathrm{~h}$, for remaining grains - 16-17 h). The EPMA maps also enable rapid localization of mineral inclusions (grain RUD15ap, bottom-left column in Fig. 1b). In addition to the observation, that the zonation seen in BSE images is perfectly mirrored, features such as resorption boundaries are also recorded

in the EPMA maps. It is also useful to examine correlations between different elements which may help in the petrogenetic interpretation. For instance, in most grains (Figs. 1b, 2a-b, 3 ), $\mathrm{Ce}$ is positively correlated with Y. However, the grain EQU-1ap (Fig. 1a) contains a rim, in which both lanthanides are antipathetically correlated. Similarly, Y and Si are negatively correlated in this domain, whereas they behaved sympathetically in the core and inner zones. Several grains RUD1-4ap, MIL-4ap and RUD2-12ap - contain small elongated domains or show sharp lines in EPMA Si-maps (bottom-left images in Figs. 2a-b, 3, respectively) showing elevated intensities of the Si signal (red colour). These are not 


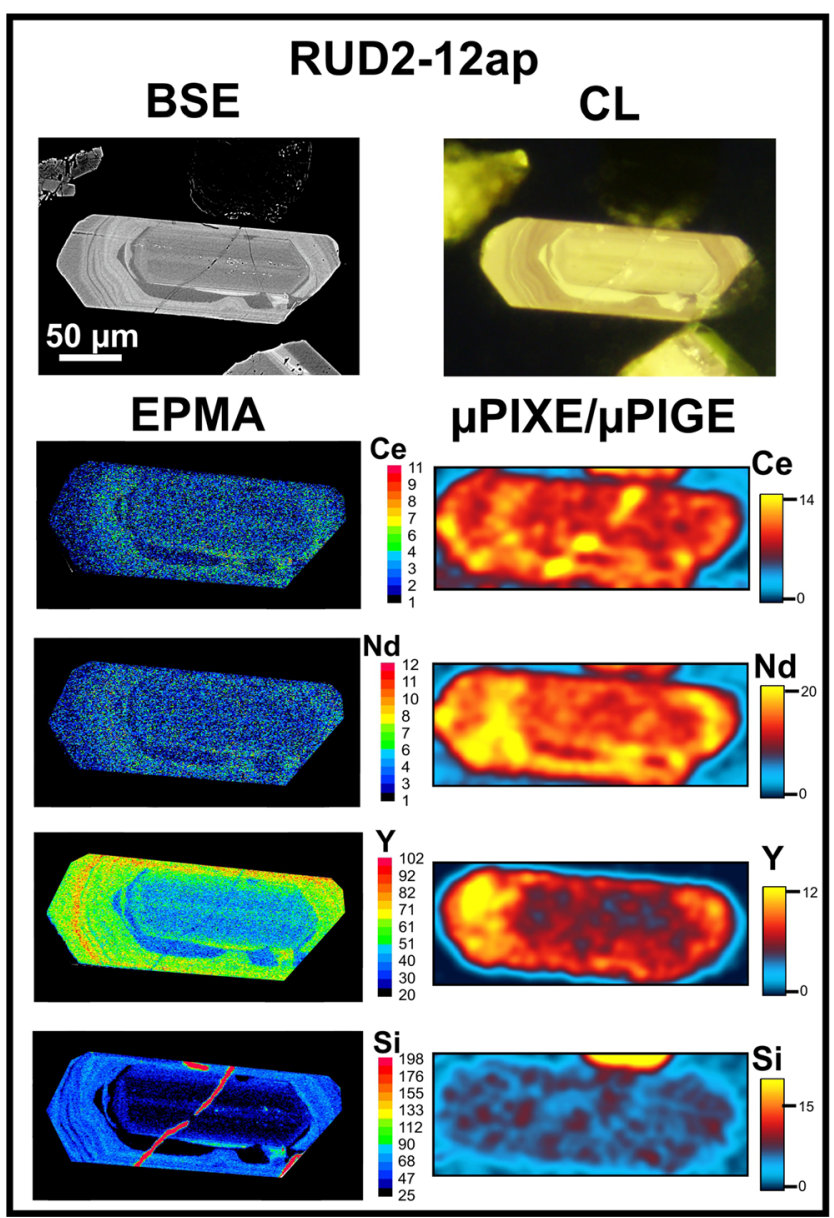

Fig. 3 Backscattered electrons (BSE; top-left), cathodoluminescence (CL; top-right) images, EPMA (bottom-left column) and $\mu$ PIXE/ $\mu$ PIGE (bottom-right column) elemental distribution maps of one fluorapatite grain - RUD2-12ap. Ce, Nd and Y were measured by $\mu$ PIXE, Si by $\mu$ PIGE. Color scale in EPMA and $\mu$ PIXE/ $\mu$ PIGE maps represents the intensity of collected X-rays [counts]

structural but most likely due to colloidal silica not removed from the thin-section surface during preparation.

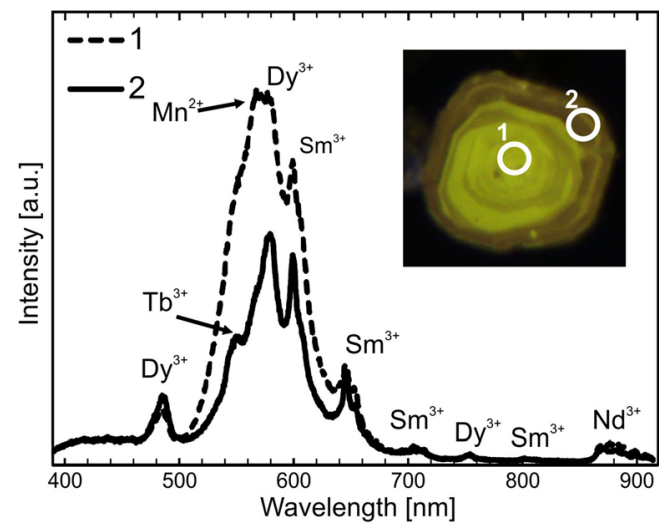

Fig. 4 Cathodoluminescence wavelength spectra of two zones from fluorapatite grain RUD1-5ap. Dashed line represents the yellow, $\mathrm{Mn}^{2+}$ activated luminescence (core), whereas the full line demonstrates $\mathrm{REE}^{3+}$ emission bands of the violet rim zone

\section{$\mu P I X E / \mu P I G E$ imaging}

The $\mu$ PIXE (and $\mu$ PIGE in case of $\mathrm{Si}$ ) elemental distribution maps show internal zoning of fluorapatite grains, however the smallest achievable beam size of $5 \mu \mathrm{m}$ (leading to pixel size $5 \times 5 \mu \mathrm{m}^{2}$ ) is too large to resolve the textural patterns in sufficient detail (bottom-right column in Figs. 1, 2, and 3). For instance, only two distinct zones are discernible in grains RUD1-5ap (bottom-right column in Fig. 1b) and RUD1-4ap (bottom-right column in Fig. 2a), whereas the thin subzones well visible in BSE and CL images and EPMA maps are not displayed. Mineral inclusions appear as round spots of higher intensity (bottom-right column in Fig. 1b). Not all features observed in the $\mu$ PIGE maps represent real compositional variations in fluorapatite. The bright yellow colour in Si maps (bottom-right columns in Figs. 1a, 2b) is derived from the silica-rich glass (on which the grains were mounted). Highenergy gamma rays are emitted from much greater depths then the low-energy Si-K X-rays, hence, the high intensity of the $\mathrm{Si}$ signal from glass detected by $\mu$ PIGE. Another artefact is the bright colour on one side of the grains (e.g. on the left side of RUD1-5ap, bottom-right column in Fig. 1b). It simply relates to the fixed position of the detector which, located on that side, collects more generated X-rays than from other parts of the grain.

For each grain we show four maps with the most visible zonation patterns (bottom-right columns in Figs. 1, 2, and 3). Elements detected by $\mu$ PIXE include $\mathrm{Ca}, \mathrm{Mn}, \mathrm{Fe}, \mathrm{As}, \mathrm{Sr}, \mathrm{Y}$, $\mathrm{La}, \mathrm{Ce}, \mathrm{Nd}, \mathrm{Tm}, \mathrm{Yb}$, Th and $\mathrm{U}$ (in addition, $\mathrm{Zr}$ and $\mathrm{Hf}$ are occasionally present), whereas $\mu$ PIGE energy spectra show peaks related to F, Na, Si and P. Three spot measurements were performed by both $\mu$ PIXE and EPMA in one grain (FOJ-5ap, Fig. 5) to compare the obtained concentrations and limits of detection. The corresponding spots were located as close to each other as possible. The energy spectra ( $\mu \mathrm{PIXE}$ and $\mu$ PIGE) of spot \#3 are given in Fig. 6. Although $\mathrm{Si}$ is usually present in the $\mu$ PIGE spectra of the fluorapatite grains studied, the spectrum of the spot measurement (Fig. 6b) does not contain any significant $\mathrm{Si}$ peak. This is probably due to low concentrations of this element in fluorapatite and the large absorption of the $\mathrm{Si}$ gamma rays from glass. The quantitative results of $\mu$ PIXE and EPMA are given in Table 3. For most elements, the $\mu$ PIXE/EPMA ratios are close to 1. Occasionally, $\mu$ PIXE measurements yielded contents twice as low as those determined by EPMA.

In addition to $\mathrm{Si}$, four $\mu \mathrm{PIGE}$ maps for $\mathrm{F}$ and $\mathrm{Na}$ were collected for two selected grains (Fig. 7a-RUD1-5ap, b RUD1-4ap) in order to verify if any compositional zoning can be detected. There is no apparent zonation in case of fluorine and only very subtle hints of zoning in Na maps. As EPMA mapping of $\mathrm{Na}$ and $\mathrm{F}$ pose difficulties due to long exposure of the sample to the electron beam and, hence, high mobility of 


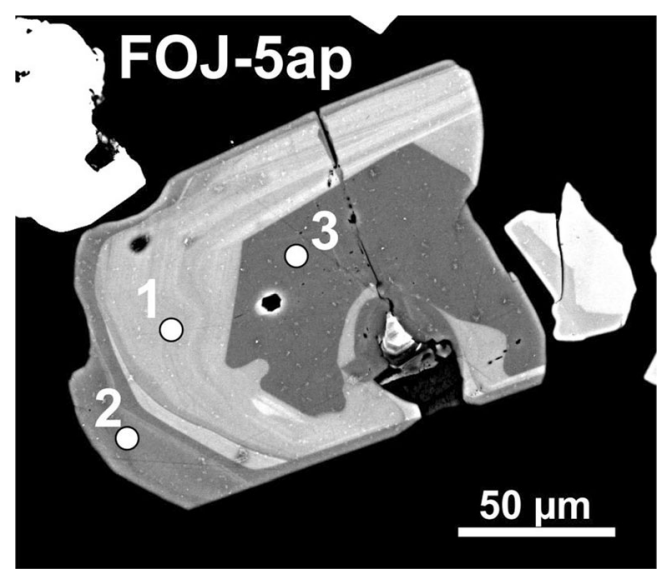

Fig. 5 BSE image of one fluorapatite grain - FOJ-5ap, in which EPMA and $\mu \mathrm{PIXE}$ spot measurements $(1,2$ and 3$)$ were performed

these elements, single spot EPMA measurements were performed for grain RUD1-5ap (Fig. 7). The BSE-bright rim is indeed enriched in Na compared to BSE-darker zones by $\sim 300$ ppm (Table 4). However, it may not be a sufficiently large concentration contrast to be discriminated as a separate zone. In case of fluorine, there are no significant variations between the measured spots (Table 4).
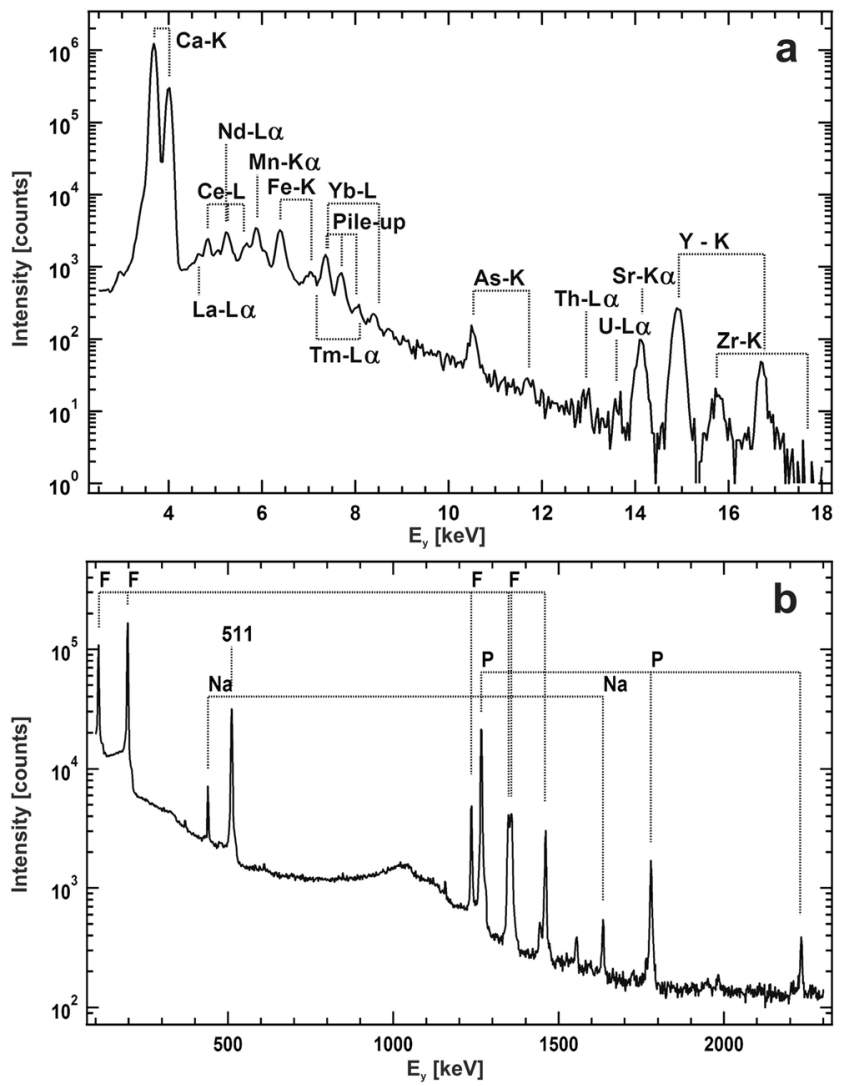

Fig. $6 \mu$ PIXE (a) and $\mu$ PIGE (b) spectra with marked X-ray/gamma ray lines of all detected elements. Line marked 511 in the PIGE spectrum is caused by positron-electron annihilation both in the background and in the sample. The source of the $1550 \mathrm{keV}$ emission is unknown

\section{Discussion}

The textural and compositional information obtained by each of the applied methods differ in terms of several important criteria. The first one is the character of the acquired data. Both BSE and CL imaging provide merely qualitative data (however, in case of CL, quantitative analysis of elements giving rise to luminescence is generally available, based on the intensity of emission bands in CL spectra). The contrast in BSE intensity allows the observation of growth zoning and reveals periods of enrichment and depletion of elements during crystal growth. In this case more detailed information is given by CL imaging. Analysis of CL spectra gives evidence of REE enrichment in BSE-bright and violet zones due to increased intensity of $\mathrm{REE}^{3+}$-activated bands. Specific emissions and resulting luminescence of fluorapatite domains may already give hints on its origin. According to present knowledge, yellow luminescence activated by $\mathrm{Mn}^{2+}$ is typical of fluorapatite crystallizing from silicic melts (and related hydrothermal fluids), whereas fluorapatite originating from alkaline or carbonatitic melts show violet CL due to an enrichment in $\mathrm{REE}^{3+}$ (Kempe and Götze 2002). Another advantage of CL imaging is the possibility to distinguish zones of different luminescence (e.g. yellow and greenish core, top-right image in Fig. 2a), which, however, display identical BSE intensity (top-left image in Fig. 2a). The presence of specific CL emissions is also helpful in selecting elements for quantitative analysis.

While BSE and CL usually provide qualitative information on compositional zoning in fluorapatite, EPMA and $\mu$ PIXE/ $\mu$ PIGE are capable of both qualitative and quantitative analysis. The two latter techniques, however, differ in terms of element-detection method. The WDS system used in EPMA is based on selection of characteristic X-rays (with specific wavelengths) by a diffracting crystal. Such mode of detection is sequential, which extends significantly the time of chemical analysis. On the other hand, an EDS system coupled with our $\mu$ PIXE set-up utilizes energy dispersion and, consequently, all elements are detected simultaneously. Such a method of detection is more rapid, but suffers from the major problem of peak overlapping. Analysing a specific X-ray line in WDS mode is in such case more advantageous due to: 1) better energy resolution, 2) the possibility of choosing a different line instead and 3) numerous corrections for most common pairs of overlapping peaks. The EDS spectra are composed of all detected element peaks, therefore, peak overlapping is an omnipresent problem. Due to similar energies of the REE Xray lines, the distinction of REE peaks is difficult. In the obtained $\mu$ PIXE spectra, only $\mathrm{La}, \mathrm{Ce}, \mathrm{Nd}, \mathrm{Tm}$ and $\mathrm{Yb}$ could be distinguished, whereas elements such as $\mathrm{Pr}$ and $\mathrm{Sm}$, most likely also present in the fluorapatite structure, failed to be discriminated On the other hand, $\mu$ PIXE highlights the presence of elements not regarded as "standard" fluorapatite 
Table 3 Results of $\mu$ PIXE and EPMA analyses placed in three growth zones in fluorapatite grain FOJ-5ap

\begin{tabular}{|c|c|c|c|c|c|c|c|c|c|}
\hline \multirow[t]{2}{*}{ Element } & \multicolumn{9}{|l|}{ FOJ-5ap } \\
\hline & $1^{*} \mu \mathrm{PIXE}$ & 1 EPMA & $\mu \mathrm{PIXE} / \mathrm{EPMA}$ ratio & $2 \mu \mathrm{PIXE}$ & 2 EPMA & $\mu \mathrm{PIXE} / \mathrm{EPMA}$ ratio & $3 \mu \mathrm{PIXE}$ & 3 EPMA & $\mu \mathrm{PIXE} / \mathrm{EPMA}$ ratio \\
\hline $\mathrm{Ca}[\mathrm{wt} \%]$ & 39.43 & 38.74 & 1.02 & 39.71 & 39.25 & 1.012 & 39.73 & 39.72 & 1.00 \\
\hline $\mathrm{Mn}[\mathrm{ppm}]$ & 367 & b.d. $* * *$ & & 379 & 448 & 0.84 & 354 & b.d. & \\
\hline $\mathrm{Fe}[\mathrm{ppm}]$ & 221 & 564 & 0.39 & 300 & 295 & 1.02 & 172 & 282 & 0.61 \\
\hline As [ppm] & b.d. & n.a. & & 23 & n.a. & & b.d. & n.a. & \\
\hline $\mathrm{Sr}[\mathrm{ppm}]$ & 108 & b.d. & & 85 & b.d. & & 136 & b.d. & \\
\hline $\mathrm{Y}[\mathrm{ppm}]$ & 2180 & 2753 & 0.79 & 357 & 817 & 0.44 & 712 & 19 & 36.84 \\
\hline $\mathrm{Zr}[\mathrm{ppm}]$ & b.d. & n.a. & & b.d. & n.a. & & 28 & n.a. & \\
\hline La [ppm] & 1569 & b.d. & & 557 & 1040 & 0.54 & 291 & b.d. & \\
\hline $\mathrm{Ce}[\mathrm{ppm}]$ & 4176 & 4430 & 0.94 & 1343 & 2435 & 0.55 & 880 & 768 & 1.15 \\
\hline $\mathrm{Nd}[\mathrm{ppm}]$ & 2480 & 4428 & 0.56 & 589 & 863 & 0.68 & 567 & 889 & 0.64 \\
\hline $\mathrm{Tm}[\mathrm{ppm}]$ & 192 & n.a. & & 52 & n.a. & & 44 & n.a. & \\
\hline $\mathrm{Yb}[\mathrm{ppm}]$ & 244 & 448 & 0.55 & b.d. & 602 & 0.08 & 74 & 655 & 0.11 \\
\hline Hf [ppm] & 53 & n.a. & & b.d. & n.a. & & b.d. & n.a. & \\
\hline Th [ppm] & 64 & b.d. & & b.d. & b.d. & & b.d. & b.d. & \\
\hline $\mathrm{U}[\mathrm{ppm}]$ & 45 & b.d. & & 23 & 192 & 0.12 & b.d. & b.d. & \\
\hline
\end{tabular}

* 1,2 and 3 represent spots marked in Fig. 7

**** b.d. - below detection limit, n.a. - not analyzed

All concentrations measured by $\mu \mathrm{PIXE}$ are normalized to $100 \%$

constituents in EPMA measurements, e.g. As, $\mathrm{Zr}$ and $\mathrm{Hf}$ (Fig. 6a). In $\mu$ PIXE, peak overlapping also causes difficulties if both light and heavy elements are being analysed by EDS. $\mathrm{K}$-lines of light elements are located in the same energy range as L-lines of heavy elements. If the concentrations of these heavy elements are sufficiently high (more than several hundreds of ppm), the cross-section of their relevant peaks (i.e. the probability of the specific electron transitions) may be large,
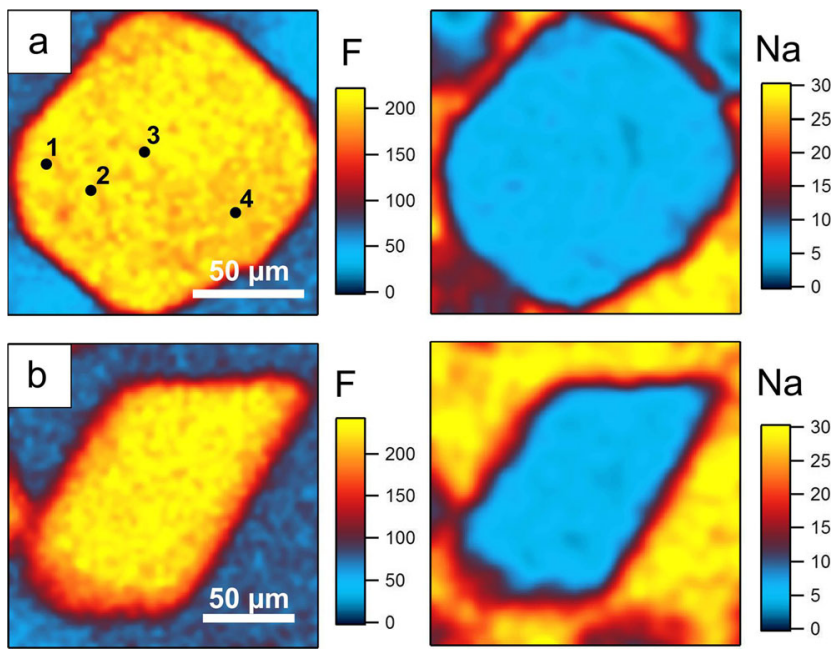

Fig. 7 Elemental distribution maps of $\mathrm{Na}$ and $\mathrm{F}$ for two fluorapatite grains obtained by $\mu$ PIGE; a - RUD1-5ap, b - RUD1-4ap. Color scale represents the intensity of collected gamma rays [counts]. The points with numbers denote the additional EMPA spot measurements presented in Table 2

thus preventing the recognition of the light elements, or vice versa. Nevertheless, for the present measurements, the problems with overlap in the $\mu$ PIXE spectra are limited because there are no interfering $\mathrm{K}$-lines, e.g. from $\mathrm{Ti}$, and the REE that are found are relatively far apart, leading to at most double overlap. For the analysis of point spectra using Gupix, the contribution of the overlap to the statistical uncertainty is calculated (Maxwell et al. 1989). It is less than a few percent in most cases, e.g. the statistical uncertainty increases from 1.9 to $3.3 \%$ for the Nd-L $\alpha$ X-ray line for sample FOJ-5ap. For elements with $\mathrm{Z}<16$ (F, Na, Si and $\mathrm{P}$ in fluorapatite), the peak overlapping may be partially overcome by using an additional $\mu$ PIGE detector. However, even among gamma ray emission lines, peaks with identical energies exist if the nuclear reaction products are the same. The identification and quantification has to be done using several lines that have different relative intensities and cross-sections. For instance, the most intense line for $\mathrm{Si}$ at $1779 \mathrm{keV}$ is at the same position as the second most intense line for P. If the Si concentration and, hence, the peak is sufficiently high, then this line may be assigned to Si.

Table 4 EPMA analyses for fluorapatite grain RUD1-5ap

\begin{tabular}{lll}
\hline Grain-point & Na [ppm] & F [wt\%] \\
\hline RUD1-5ap-1 & 1205 & 3.68 \\
RUD1-5ap-2 & 927 & 3.65 \\
RUD1-5ap-3 & 957 & 3.61 \\
RUD1-5ap-4 & 786 & 3.65 \\
\hline
\end{tabular}


This applies to the maps in Figs. 1, 2, and 3 where the Si signal derives from the silica glass. The deconvolution between $\mathrm{Si}$ and $\mathrm{P}$ is further supported by the presence of other gamma ray lines. In the case of the spot measurement, however, the intensity ratio between all P-peaks indicates that the peak at $1779 \mathrm{keV}$ corresponds most probably exclusively to $\mathrm{P}$ (Fig. 6b). For the two grains EQU-1ap and MIL-4ap (bottom-right columns in Figs. 1a, 2b), the Si map shows most probably no contribution of $\mathrm{P}$, in which case the fluorapatite would be more P-rich than the surrounding silica glass. The grain RUD2-12ap (bottom-right column in Fig. 3), however, may show some contribution of $\mathrm{P}$, as the contrast between the silica glass and the grain is not that significant. In case of both $\mu$ PIXE and $\mu$ PIGE, a careful analysis of all peaks present in the spectra and their ratios, as well as a basic knowledge on the possible composition of the studied fluorapatite, are crucial in qualitative and quantitative analysis of mineral composition. Taking into account the analytical conditions applied in both EPMA and $\mu$ PIXE/ $\mu$ PIGE, EPMA of Si and P concentrations should provide lower detection limits (due to no peak overlapping in either EDS or WDS spectra) than $\mu$ PIGE.

The EPMA-generated elemental distribution maps discussed in this study are qualitative. Transformation of Xray intensities into concentrations is principally possible, but would have required longer acquisition times (additional background measurements in each spot). In contrast, $\mu \mathrm{PIXE} /$ $\mu$ PIGE maps consist of multiple point measurements, each with their relevant energy spectra. Therefore, element concentrations can be readily calculated for every spot.

Unlike the presented maps, the spot measurements performed by EPMA and $\mu$ PIXE allow a quantitative comparison of both techniques. Our results show that the $\mu$ PIXE spot compared to EPMA measurements provide lower detection limits (by one or even two orders of magnitude, Table 2) for the given dwell times employed in this analysis. When similar acquisition times are applied in both techniques, lower detection limits are expected to be achieved by $\mu$ PIXE. This is due to the lower peak-to-background ratio, resulting from lower Bremsstrahlung generated by ions compared to electrons (Wang and Nastasi 2010). In such a case, the only shortcoming is the potential overlapping of REE peaks in the $\mu$ PIXE energy spectra, which may result in increased detection limits (however, as discussed earlier, this may not always be a problem, as evidenced by our results). On the other hand, electron probe microanalysis is capable of achieving similarly low (or even lower) detection limits as our $\mu$ PIXE measurements (due to significantly better peak resolution in the energy in WDS spectra). This would, however, require significantly longer measuring times (especially for trace elements), far exceeding those applied in $\mu$ PIXE. In the case of mapping, similar acquisition times in EPMA and $\mu$ PIXE would also result in lower detection limits for the latter technique, as the counting time of a single spot during EPMA mapping is very short. The comparison of the acquisition times for a qualitative map performed by EPMA (16-17 h) and quantitative map produced by $\mu$ PIXE $(3-4 \mathrm{~h})$ evidently demonstrates the advantage of $\mu$ PIXE.

The discrepancies in element concentrations between $\mu$ PIXE and EPMA (Table 3) may also be related to different acquisition times and peak-overlap resolution of each method. However also the interaction volume (mainly the depth) from which the characteristic X-rays are generated, has to be taken into consideration. In EPMA spot measurements, the interaction depth for the applied analytical conditions $(20 \mathrm{kV}, 10 \mu \mathrm{m}$ beam diameter) in fluorapatite is ca. $2.5 \mu \mathrm{m}$ for the majority of measured elements, including $\mathrm{La}, \mathrm{Ce}, \mathrm{Nd}, \mathrm{Y}$ (a density of $3.2 \mathrm{~g} / \mathrm{cm}^{3}$ for fluorapatite has been assumed), based on Monte Carlo simulations. In $\mu$ PIXE spot measurements, the beam diameter is slightly smaller $\left(8 \times 5 \mu \mathrm{m}^{2}\right)$, which decreases the width of the interaction volume, however, the depth is significantly larger compared to EPMA. For $\mu$ PIXE, the analysis depths can be calculated for each element by Gupix and are listed in Table 5. The analysis depth depends on two factors: the cross-section for ionisation, which decreases with depth, and the absorption of X-rays which increases with depth. Therefore, the analysis depths can be determined only for a fixed percentage of the total yield of detected X-rays (here it is $67 \%, 90 \%$ and $95 \%$ ). The analysis depth of $\mu$ PIGE is in general much higher because the absorption of the gamma rays in the sample can be neglected and it depends only on the reaction cross-section as a function of depth. The analysis depths for $\mathrm{F}$ and $\mathrm{Na}$ are presented in Table 5 for gamma rays of $197 \mathrm{keV}$ and $440 \mathrm{keV}$ energy, respectively. The width of the $\mu$ PIXE interaction volume depends exclusively on the beam size and remains constant from the sample surface until near the end of the proton range (unlike the electron based techniques where the interaction volume is pear-shaped and the diameter increases with depth). The analysis depths shown in Table 5 indicate that the information given by $\mu$ PIXE and $\mu$ PIGE measurements comes from greater depths compared to EPMA (especially in case of F, Na, Sr, Y, Zr, Th and U), which may hinder the analysis of heterogeneous samples, e.g. strongly zoned fluorapatite. Such discrepancy in interaction volume may be also evidenced by different concentrations of the same element in spot measurements performed by EPMA and $\mu$ PIXE (Table 3).

The last important feature worth discussing is the spatial resolution of the obtained images, important for textural and compositional studies of zoned minerals. The spatial resolution of an image depends on the beam size and the interaction volume, from which the back-scattered electrons, visible light or X-rays/gamma rays are emitted. Both BSE and CL images distinctly display the most detailed growth textures, where even the thinnest zones are visualized. The interaction volume for back-scattered electrons is relatively small, resulting in high lateral resolution. Moreover, better depth resolution is 
Table 5 The analysis depths for three fractions of the total yield of detected X-ray quanta, given for all elements measured by $\mu$ PIXE and two elements measured by $\mu$ PIGE

\begin{tabular}{lllll}
\hline \multirow{2}{*}{ Element } & X-ray/Gamma line & \multicolumn{2}{l}{ Depth $(\mu \mathrm{m})$ for given fractional yield } \\
\cline { 3 - 5 } & & $67 \%$ & $90 \%$ & $95 \%$ \\
\hline $\mathrm{F}$ & $\gamma$ & 32 & 50 & 53 \\
$\mathrm{Na}$ & $\gamma$ & 43 & 56 & 60 \\
$\mathrm{Ca}$ & $\mathrm{K}$ & 7 & 15 & 19 \\
$\mathrm{Mn}$ & $\mathrm{K}$ & 8 & 16 & 21 \\
$\mathrm{Fe}$ & $\mathrm{K}$ & 9 & 19 & 25 \\
$\mathrm{As}$ & $\mathrm{K}$ & 21 & 39 & 47 \\
$\mathrm{Sr}$ & $\mathrm{K}$ & 25 & 44 & 52 \\
$\mathrm{Y}$ & $\mathrm{K}$ & 25 & 44 & 52 \\
$\mathrm{Zr}$ & $\mathrm{K}$ & 26 & 45 & 52 \\
$\mathrm{La}$ & $\mathrm{L} \alpha$ & 4 & 9 & 12 \\
$\mathrm{Ce}$ & $\mathrm{L} \alpha$ & 5 & 10 & 13 \\
$\mathrm{Nd}$ & $\mathrm{L} \alpha$ & 6 & 12 & 15 \\
$\mathrm{Tm}$ & $\mathrm{L} \alpha$ & 12 & 24 & 31 \\
$\mathrm{Yb}$ & $\mathrm{L} \alpha$ & 13 & 25 & 32 \\
$\mathrm{Hf}$ & $\mathrm{L} \alpha$ & 14 & 28 & 36 \\
$\mathrm{~W}$ & $\mathrm{~L} \alpha$ & 16 & 31 & 39 \\
$\mathrm{Th}$ & $\mathrm{L} \alpha$ & 24 & 43 & 51 \\
$\mathrm{U}$ & $\mathrm{L} \alpha$ & 25 & 44 & 52 \\
\hline
\end{tabular}

achieved for low-energy elements, from which the electrons are emitted only in the near-surface part of the specimen (due to absorption in greater depths). In cathodoluminescence (coupled with an optical microscope), the electron beam is defocused and, thus, a large part of the surface is excited. The CL signal is generated over a wide range of depths: from the sample surface to several $\mu \mathrm{m}$ below (Götze and Kempe 2008). Compared to characteristic X-rays, the interaction volume of CL is greater, however, short wavelengths of visible light ensure high spatial resolution. Moreover, the optical resolution of the microscope in use may further limit the spatial resolution of a CL image. If, however, CL is coupled with EPMA, a focused electron beam ensures a smaller analytical spot and, hence, decreased interaction volume from which both characteristic X-rays and CL signal are generated. In this case, spatial resolution of CL imaging is similar to that of EPMA mapping (e.g. MacRae et al. 2013).

The level of details seen in EPMA distribution maps indicates that with a sufficiently small pixel size $\left(1 \times 1 \mu \mathrm{m}^{2}\right.$ in this study), the method is capable of reproducing the same spatial resolution as BSE and CL images. With a beam diameter of $1 \mu \mathrm{m}$, the interaction volume is ca. $2 \mu \mathrm{m} \times 2 \mu \mathrm{m}$ in size, therefore no significant overlap of the adjacent spots is present.

The relatively low spatial resolution of the maps obtained by our $\mu$ PIXE/ $\mu$ PIGE set-up can be explained by two facts: 1 ) the high-energy proton beam is inherently more difficult to focus compared to an electron beam, and 2) the set-up used in this study is not yet optimised for small beam sizes. A smaller beam size and, hence, better lateral resolution could be achieved by further modernisation of the set-up, with an emphasis on improving the focussing properties. State-of-theart ion micro-beamlines have beam spots smaller than $1 \mu \mathrm{m}$ (Ryan 2011). However, in addition to features which limit the lateral resolution, the overall spatial resolution of the $\mu$ PIXE maps is also influenced by the analysis depth. The variation of the analysis depth can lead to differences in elemental distributions obtained by $\mathrm{K}$ and L X-ray lines or L and M X-ray lines of the same element if the sample is inhomogeneous in depth (e.g. Munnik et al. 1999). In case of very thin zones (several $\mu \mathrm{m}$ in width, e.g. in grain RUD1-4ap, Fig. 2a) the Xray signal generated by $\mu$ PIXE can partially come from the adjacent growth zone. In such case, these zones may not be sufficiently visible on $\mu$ PIXE maps.

\section{Conclusions}

Each technique applied in this study visualized the traceelement zoning within fluorapatite single-crystals in a different way, in terms of the character of the data (qualitative vs. quantitative), method of detection (WDS vs. EDS) and quality (detection limits, spatial resolution). The following conclusions can be drawn from the acquired results:

1) For the separation of REE X-ray lines, EPMA-WDS is a well suitable technique whereas extensive overlapping of peaks may pose problems in the application of $\mu \mathrm{PIXE} /$ $\mu$ PIGE-EDS techniques.

2) The EPMA element distribution maps produced in this study give only a qualitative image of compositional variations in fluorapatite. $\mu \mathrm{PIXE} / \mu \mathrm{PIGE}$ maps are quantitative, meaning that element concentrations may be calculated for each spot represented by an energy spectrum.

3) The $\mu$ PIXE mapping (including current set-up) is capable of achieving low detection limits more rapidly (especially for trace elements which is crucial in terms of accessory minerals), compared to EPMA mapping, unless complex trace element peak overlaps are present.

4) The highest spatial resolution is demonstrated by BSE and CL images which enable a detailed investigation of fluorapatite textures. Element mapping by EPMA is able to reproduce nearly the same level of resolution with sufficiently small pixel size of $1 \times 1 \mu^{2}$. The beam size generated by the applied $\mu$ PIXE set-up was not sufficiently small to resolve minor textural features.

5) Interaction volume of each of the applied methods (CL, EPMA, $\mu$ PIXE/ $\mu$ PIGE) can influence the detection limits, element concentrations and spatial resolution of 
elemental distribution maps if the analysed sample is inhomogeneous in depth (especially in case of $\mu \mathrm{PIXE}$ ).

All studied techniques are complementary and the application of all of them produces a full characterization of compositional variations in minerals on a micro-scale. Imaging in BSE and CL modes is most suitable for primary textural investigations. Major compositional variations can be visualized rapidly by $\mu$ PIXE and $\mu$ PIGE, especially by quantitative mapping of trace elements due to low detection limits and the lack of a need for reference materials. The current $\mu$ PIXE/ $\mu$ PIGE set-up, however, does not provide sufficiently high spatial resolution, especially when applied to minerals with complex growth patterns. Based on the results, a smaller amount of material can be further selected for more time-consuming EPMA-WDS imaging, which ensures high spatial resolution and good peak separation.

Acknowledgements We thank the crew operating the HZDR Tandem accelerator for their valuable technical assistance with the $\mu$ PIXE measurements. We also thank Axel Renno (Helmholtz Institute Freiberg for Resource Technology, HZDR) for helpful discussions. Constructive reviews by Colin MacRae, Martin J. Streck, Hans-Peter Schertl, and an anonymous expert are gratefully acknowledged. This work has been supported by the European Community as an Integrating Activity 'Support of Public and Industrial Research Using Ion Beam Technology (SPIRIT)' under EC contract no. 227012 and the Polish Government NCN grant no. 2011/01/N/ST10/04756.

Open Access This article is distributed under the terms of the Creative Commons Attribution 4.0 International License (http:// creativecommons.org/licenses/by/4.0/), which permits unrestricted use, distribution, and reproduction in any medium, provided you give appropriate credit to the original author(s) and the source, provide a link to the Creative Commons license, and indicate if changes were made.

\section{References}

Allègre CJ, Treuil M, Minster J-F, Minster B, Albarède F (1977) Systematic use of trace elements in igneous processes. Contrib Mineral Petr 60:57-75

Armstrong JT (1995) CITZAF: a package of correction programs for the quantitative electron microbeam X-ray-analysis of thick polished materials, thin films, and particles. Microb Anal 4:177-200

Belousova EA, Griffin WL, O’Reilly SY, Fisher NI (2002) Apatite as an indicator mineral for mineral exploration: trace-element compositions and their relationship to host rock type. J Geochem Explor 76:45-69

Campbell JL, Hopman TL, Maxwell JA, Nejedly Z (2000) The Guelph PIXE software package III: Alternative proton database. Nucl Instrum Meth B 170:193-204

Churikova TG, Ivanov BV, Eichelberger J, Wörner G, Browne B, Izbekov P (2013) Major and trace element zoning in plagioclase from Kizimen Volcano (Kamchatka): Insights into magmachamber processes. J Volcanol Seismol 7:112-130

Deering CD, Bachmann O (2010) Trace element indicators of crystal accumulation in silicic igneous rocks. Earth Planet Sc Lett 297: $324-331$
Dekov VM, Kamenov GD, Abrasheva MD, Capaccioni B, Munnik F (2013) Mineralogical and geochemical investigation of seafloor massive sulfides from Panarea Platform (Aeolian Arc, Tyrrhenian Sea). Chem Geol 335:136-148

Dempster TJ, Jolivet M, Tubrett MN, Braithwaite CJR (2003) Magmatic zoning in apatite: a monitor of porosity and permeability change in granites. Contrib Mineral Petr 145:568-577

Filippelli GM, Delaney ML (1993) The effects of manganese(II) and iron(II) on the cathodoluminescence signal in synthetic apatite. J Sed Petrol 63:167-173

Fuchs S, Przybylowicz WJ, Williams-Jones AE (2014) Elemental imaging of organic matter and associated metals in ore deposits using micro PIXE and micro-EBS. Nucl Instrum Meth B 318(A):157-162

Ginibre C, Kronz A, Wörner G (2002) High-resolution quantitative imaging of plagioclase composition using accumulated backscattered electron images: new constraints on oscillatory zoning. Contrib Mineral Petrol 142:436-448

Götze J (2012) Application of cathodoluminescence microscopy and spectroscopy in geosciences. Microsc Microanal 18:1270-1284

Götze J, Kempe U (2008) A comparison of optical microscope- and scanning electron microscope-based cathodoluminescence (CL) imaging and spectroscopy applied to geosciences. Mineral Mag 72: 909924

Götze J, Heimann RB, Hildebrandt H, Gburek U (2001) Microstructural investigation into calcium phosphate biomaterials by spatially resolved cathodoluminescence. Materialwiss Werkst 32:130-136

Götze J, Schertl HP, Neuser RD, Kempe U, Hanchar JM (2013) Optical microscope-cathodoluminescence (OM-CL) imaging as a powerful tool to reveal internal textures of minerals. Miner Petrol 107: 373-392

Habermann D, Götte T, Meijer J, Stephan A, Richter DK, Niklas JR (2000) High resolution rare-earth elements analyses of natural apatite and its application in geo-sciences: Combined micro-PIXE, quantitative CL spectroscopy and electron spin resonance analyses. Nucl Instrum Meth B 161-163:846-851

Johansson SAE, Campbell JL, Malmqvist KG (1995) Particle-induced Xray emission spectrometry (PIXE). Wiley-Interscience, New York

Kaneko Y, Fukui K, Hashimoto S (2005) Electron channeling contrast imaging of dislocation structures in fatigued austenitic stainless steels. Mater Sci Eng A 400-401:413-417

Kempe U, Götze J (2002) Cathodoluminescence (CL) behaviour and crystal chemistry of apatite from rare-metal deposits. Mineral Mag 66:135-156

Li X, Han T, Zhu X, Li Y, Zheng Y, Shen H (2013) A mineralogical application of micro-PIXE technique: The Ni-Mo-PGE polymetallic layer of black shales in Zunyi region, South China. Nucl Instrum Meth B 308:1-5

Lisowiec K, Słaby E, Förster HJ, Götze J (2015) Polytopic Vector Analysis (PVA) modelling of whole-rock and apatite chemistry from the Karkonosze composite pluton (Poland, Czech Republic). Lithos 230:105-120

Lloyd GE (1987) Atomic number and crystallographic contrast images with the SEM: a review of backscattered electron techniques. Mineral Mag 51:3-19

MacRae CM, Wilson NC, Torpy A, Dacidson CJ (2012) Hyperspectral $\mathrm{CL}$ imaging and analysis extending from UV to NIR. Microsc Microanal 18:1239-1245

MacRae CM, Wilson NC, Torpy A (2013) Hyperspectral cathodoluminescence. Miner Petrol 107(3):429-440

Maxwell JA, Campbell JL, Teesdale WJ (1989) The Guelph PIXE software package. Nucl Instrum Meth B 43:218-230

McLeod GW, Dempster TJ, Faithfull JW (2011) Deciphering magmamixing processes using zoned titanite from the Ross of Mull granite, Scotland. J Petrol 52:55-82 
Morgan GB, London D (1996) Optimizing the electron microprobe analysis of hydrous alkali aluminosilicate glasses. Am Mineral 81: $1176-1185$

Mosenfelder JL (2000) Pressure dependence of hydroxyl solubility in coesite. Phys Chem Miner 27:610-617

Munnik F, Sjöland KA, Vittiglio G, Ingelbrecht C, Wätjen U (1999) Nuclear microprobe study of metal segregation in quaternary bronze. Nucl Instrum Meth B 158:281-286

Nasdala L, Kronz A, Grambole D, Trullenque G (2007) Effects of irradiation damage on the back-scattering of electrons: silicon-implanted silicon. Am Mineral 92:1768-1771

Nasdala L, Kronz A, Wirth R, Kennedy A (2009) The phenomenon of deficient electron microprobe totals in radiation-damaged and altered zircon. Geochim Cosmochim Acta 73:1637-1650

Neuser RD, Bruhn F, Götze J, Habermann D, Richter DK (1995) Kathodolumineszenz: Methodik und Anwendung. Zbl Geo Pal 1(2):287-306

Nielsen CH, Sigurdsson H (1981) Quantitative methods for electron microprobe analysis of sodium in natural and synthetic glasses. Am Mineral 66:547-552

North-Valencia SN, Carpenter PK, Jolliff BL, Korotev RL (2014) Using electron-probe microanalysis and quantitative compositional mapping to study lithic clasts in lunar meteorites NWA 2727 and NWA 3170. Microsc Microanal 20:714-715

Perseil EA, Blanc P, Ohnenstetter D (2000) As-bearing fluorapatite in manganiferous deposits from St. Marcel-Praborna, Val d'Aosta, Italy. Can Mineral 38:101-117

Prior DJ, Boyle AP, Brenker F, Cheadle MC, Day A, Lopez G, Peruzzo L, Potts GJ, Reddy S, Spiess R, Timms NE, Trimby P, Wheeler J, Zetterström L (1999) The application of electron backscatter diffraction and orientation contrast imaging in the SEM to textural problems in rocks. Am Mineral 84:1741-1759

Przywóski L (2006) Chemical and CL study on apatite as an indicator of Karkonosze granite petrogenesis. MSc thesis, University of Warsaw

Reed SJB (2005) Electron microprobe analysis and scanning electron microscopy in geology. Cambridge University Press

Reimold WU, Przybylowicz W, Koeberl C (1999) Micro-PIXE analysis of varied sulfide populations from the Ventersdorp Contact Reef, Witwatersrand basin, South Africa. Nucl Instrum Meth B 158:593-598

Ryan CG (2000) Quantitative trace element imaging using PIXE and the nuclear microprobe. Int J Imag Syst Tech 11:219-230

Ryan CG (2011) PIXE and the nuclear microprobe: tools for quantitative imaging of complex natural materials. Nucl Instrum Meth B 269: $2151-2162$
Sha LK, Chappell BW (1999) Apatite chemical composition, determined by electron microprobe and laser-ablation inductively coupled plasma mass spectrometry, as a probe into granite petrogenesis. Geochim Cosmochim Acta 63:3861-3881

Słaby E (2006) Record of magma differentiation in apatite from Karkonosze hybrids - preliminary results. Miner Soc Poland Spec Pap 29:196-199

Słaby E, Martin H (2005) Mechanisms of differentiation of the Karkonosze granite. Miner Soc Poland Spec Pap 26:264-267

Słaby E, Martin H (2008) Mafic and Felsic Magma Interaction in Granites: the Hercynian Karkonosze Pluton (Sudetes, Bohemian Massif). J Petrol 49:353-391

Słaby E, Galbarczyk-Gąsiorowska L, Seltmann R, Müller A (2007a) Alkali feldspar megacryst growth: geochemical modelling. Miner Petrol 68:1-29

Słaby E, Seltmann R, Kober B, Müller A, Galbarczyk-Gąsiorowska L, Jeffries T (2007b) LREE distribution patterns in zoned alkali feldspar megacrysts - implication for parental melt composition. Mineral Mag 71:193-217

Spray JG, Rae DA (1995) Quantitative electron-microprobe analysis of alkali silicate glasses: a review and user guide. Can Mineral $33: 323-332$

Stock MJ, Humphreys MCS, Smith VC, Johnson RD, Pyle DM, EIMF (2015) New constraints on electron-beam induced halogen migration in apatite. Am Mineral 100:281-293

Stormer JC Jr, Pierson ML, Tacker RC (1993) Variation of F and Cl X-ray intensity due to anisotropic diffusion in apatite during electron microprobe analysis. Am Mineral 78:641-648

Streck MJ (2008) Minerals textures and zoning as evidence for open system processes. In: Putirka KD, Tepley FJ (eds) Minerals, inclusions and volcanic processes. Rev Mineral Geochem, vol.69 Mineral Soc Am, Washington DC, 595-622

Vagelli G, Borghi A, Cossio R, Mazzoli C, Olmi F (2003) Comparison between major and trace element concentrations in garnet performed by EPMA and micro-PIXE techniques. Spectrochim Acta B 58: 699-709

Wang Y, Nastasi M (2010) Handbook of modern ion beam materials analysis. Materials Research Society

Wiedenbeck M, Bédard LP, Bugoi R, Horan M, Linge K, Merchel S, Morales LFG, Savard D, Souders AK, Sylvester P (2014) GGR biennial critical review: analytical developments since 2012 . Geostand Geoanal Res 38(4):467-512 